\title{
Field-effect biosensor for acetoin detection during fermentation process of alcoholic beverages
}

\author{
$\underline{D_{\text {. Molinnus }}{ }^{1,2}}$, L. Muschallik ${ }^{1}$, M. Jablonski ${ }^{1}$, J. Bongaerts ${ }^{1}$, T. Wagner ${ }^{1,3}$, T. Selmer ${ }^{1}$, P. Siegert $^{1}$, \\ M. Keusgen ${ }^{2}$, M. J. Schöning ${ }^{1,3}$ \\ ${ }^{1}$ Institute of Nano- and Biotechnologies (INB), FH Aachen, Campus Jülich, Heinrich-Mußmannstr. 1, \\ 52428 Jülich, Germany \\ ${ }^{2}$ Institute of Pharmaceutical Chemistry, Philipps-University Marburg, Wilhelm-Roser-Str. 2, 35032 \\ Marburg, Germany \\ ${ }^{3}$ Institute of Complex Systems 8 (ICS-8), Forschungszentrum Jülich GmbH, Wilhelm-Johnen-Str. 6, \\ 52425 Jülich \\ molinnus@fh-aachen.de
}

\begin{abstract}
A capacitive electrolyte-insulator-semiconductor (EIS) sensor with an immobilized enzyme acetoin reductase for the detection of acetoin/diacetyl has been presented for the first time. The enzyme butane-2,3-diol dehydrogenase (acetoin reductase) catalyzes the reduction of acetoin/diacetyl to butane-2,3-diol, inducing a pH change which can be monitored by the EIS sensor. With the developed acetoin/diacetyl biosensor, acetoin in the concentration range between $10 \mu \mathrm{M}$ and $100 \mu \mathrm{M}$ can be detected, measured in buffer solution of $\mathrm{pH} 7.1$.
\end{abstract}

Key words: acetoin/diacetyl biosensor, acetoin reductase, field-effect EIS structure, diluted wine samples.

\section{Introduction}

Acetoin and diacetyl are used in e.g., foods, cosmetics or as flavor and fragrance ${ }^{1}$. Both components are key parameters during the fermentation process of alcoholic beverages (beer or wine) since their buttery-like taste can influence their quality ${ }^{2}$. Hence, the detection of acetoin/diacetyl during fermentation processes could not only monitor the quality of the process but also could avoid unnecessary maturation time.

\section{Results and discussions}

In this work, a capacitive electrolyte-insulatorsemiconductor (EIS) field-effect biosensor for the detection of acetoin has been presented. The EIS sensor (see Fig. 1) has been modified with the recently characterized enzyme acetoin reductase $^{3}$ (also referred to butane-2,3-diol dehydrogenase) from $B$. clausii DSM $8716^{\top}$ for the reduction of acetoin to 2,3-butanediol, while $\mathrm{NADH}$ serves as cofactor. Fig. 2 shows the dynamic response of the developed acetoin biosensor measured in TRIS-HCl buffer containing $150 \mathrm{mM} \mathrm{NaCl}(\mathrm{pH}$ 7.1) with acetoin concentrations in the range between $1 \mu \mathrm{M}$ and $500 \mu \mathrm{M}$. The sensor's ability has been investigated using constant-capacitance measurements, and a linear behavior in the concentration range between $10 \mu \mathrm{M}$ and $90 \mu \mathrm{M}$ with a sensitivity of $65 \mathrm{mV} / \mathrm{dec}$ is achieved. Furthermore, preliminary experiments in wine have been successfully carried out.

\section{Conclusions}

An acetoin biosensor has been developed based on an EIS structure with an immobilized enzyme acetoin reductase. The biosensor behavior was studied with regard to sensitivity in the linear concentration range, response time, hysteresis and long-term behavior.

\section{Acknowledgments}

The authors thank the Ministery of Innovation, Science and Research of the state of North Rhine-Westphalia for financial support (funding program FH-Struktur 2016). 


\section{References}

[1] Z. Xiao, X. Wang, Y. Huang, F. Huo, X. Zhu, L. Xi, J.R. Lu, Thermophilic fermentation of acetoin and 2,3-butanediol by a novel Geobacillus strain, Biotechnology for Biofuels 5, 88-89 (2012); doi: 10.1186/1754-6834-5-88

[2] P. Romano, G. Suzzi, Origin and production of acetoin during wine yeast fermentation, Applied and Environmental Microbiology 2, 309-314 (1996),

PMCID: PMC1388762
[3] L. Muschallik, D. Molinnus, J. Bongaerts, M. Pohl, T. Wagner, M. J. Schöning, P. Siegert, T. Selmer, $(R, R)$-Butane-2,3-diol dehydrogenase from Bacillus clausii DSM $8716^{\top}$ : Cloning and expression of the bdhA-gene, and initial characterization of enzyme, Journal of Biotechnology 258, 41-50 (2017), doi: 10.1016/j.jbiotec.2017.07.020

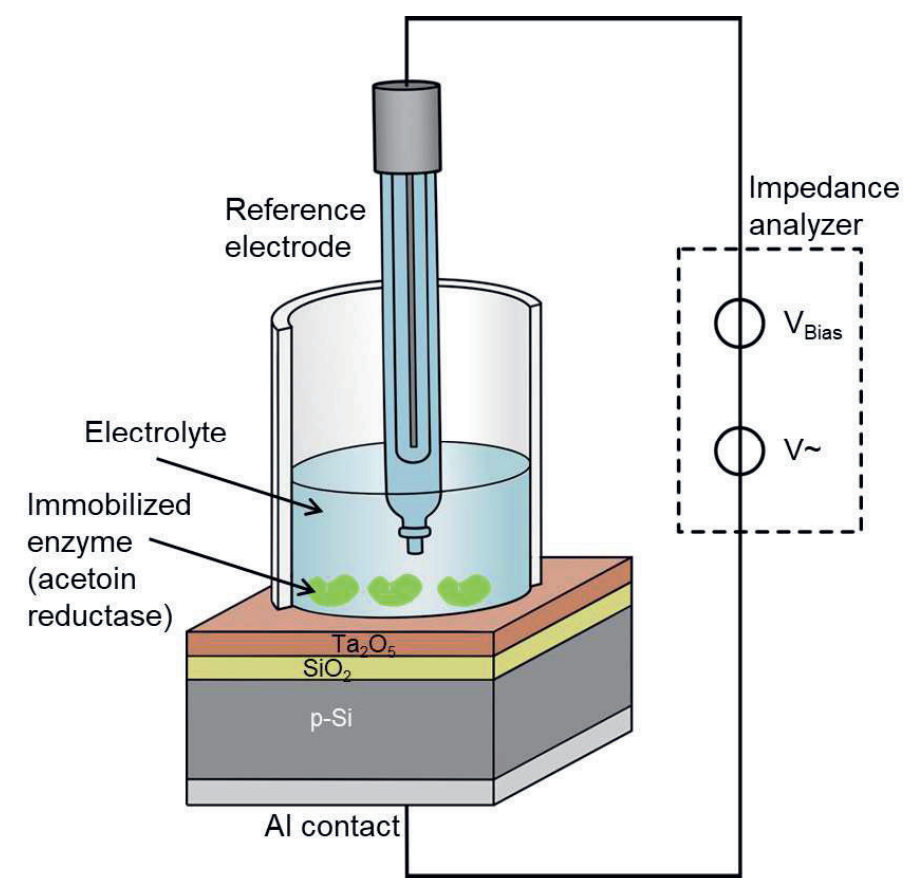

Fig.1. Schematic of the acetoin/diacetyl biosensor consisting of an EIS sensor (Al-p-Si-SiO $\left.{ }_{2}-\mathrm{Ta}_{2} \mathrm{O}_{5}\right)$ with the immobilized enzyme acetoin reductase.

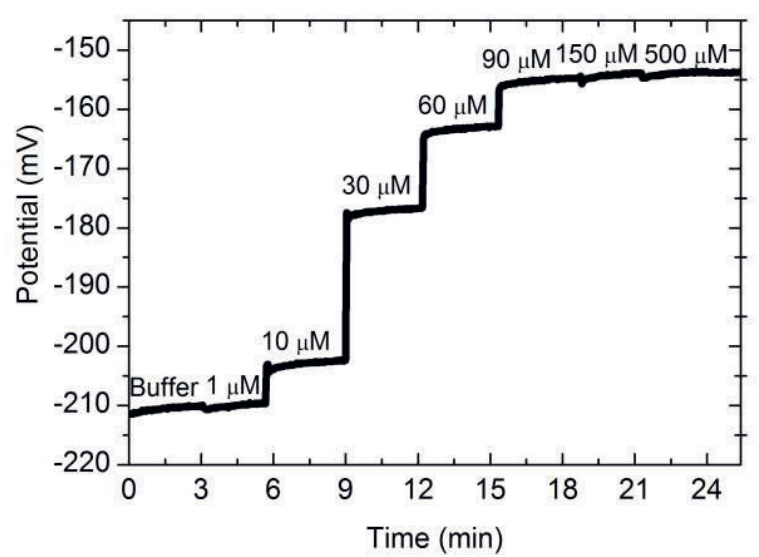

Fig.2. Dynamic response of the acetoin biosensor chip measured in an acetoin concentration range between $1 \mu \mathrm{M}$ and $500 \mu \mathrm{M}$. 